IZA DP No. 5676

Immigration and Innovation in European Regions

Ceren Ozgen

Peter Nijkamp

Jacques Poot

April 2011 


\title{
Immigration and Innovation in European Regions
}

\author{
Ceren Ozgen \\ VU University Amsterdam \\ Peter Nijkamp \\ VU University Amsterdam \\ Jacques Poot \\ NIDEA, University of Waikato \\ and IZA
}

\section{Discussion Paper No. 5676 \\ April 2011}

\author{
IZA \\ P.O. Box 7240 \\ 53072 Bonn \\ Germany \\ Phone: +49-228-3894-0 \\ Fax: +49-228-3894-180 \\ E-mail: iza@iza.org
}

\begin{abstract}
Any opinions expressed here are those of the author(s) and not those of IZA. Research published in this series may include views on policy, but the institute itself takes no institutional policy positions.

The Institute for the Study of Labor (IZA) in Bonn is a local and virtual international research center and a place of communication between science, politics and business. IZA is an independent nonprofit organization supported by Deutsche Post Foundation. The center is associated with the University of Bonn and offers a stimulating research environment through its international network, workshops and conferences, data service, project support, research visits and doctoral program. IZA engages in (i) original and internationally competitive research in all fields of labor economics, (ii) development of policy concepts, and (iii) dissemination of research results and concepts to the interested public.
\end{abstract}

IZA Discussion Papers often represent preliminary work and are circulated to encourage discussion. Citation of such a paper should account for its provisional character. A revised version may be available directly from the author. 
IZA Discussion Paper No. 5676

April 2011

\section{ABSTRACT}

\section{Immigration and Innovation in European Regions ${ }^{*}$}

The concentration of people with diverse socio-cultural backgrounds in particular geographic areas may boost the creation of new ideas, knowledge spillovers, entrepreneurship, and economic growth. In this paper we measure the impact of the size, skills, and diversity of immigration on the innovativeness of host regions. For this purpose we construct a panel of data on 170 regions in Europe (NUTS 2 level) for the periods 1991-1995 and 2001-2005. Innovation outcomes are measured by means of the number of patent applications per million inhabitants. Given the geographical concentration and subsequent diffusion of innovation activity, and the spatial selectivity of immigrants' location choices, we take account of spatial dependence and of the endogeneity of immigrant settlement in our econometric modelling. We use the location of McDonald's restaurants as a novel instrument for immigration. The results confirm that innovation is clearly a function of regional accessibility, industrial structure, human capital, and GDP growth. In addition, patent applications are positively affected by the diversity of the immigrant community beyond a critical minimum level. An increase in the fractionalization index by 0.1 from the regional mean of 0.5 increases patent applications per million inhabitants by about 0.2 percent. Moreover, the average skill level of immigrants (proxied by global regions of origin) also affects patent applications. In contrast, an increasing share of foreigners in the population does not conclusively impact on patent applications. Therefore, a distinct composition of immigrants from different backgrounds is a more important driving force for innovation than the sheer size of the immigrant population in a certain locality.

JEL Classification: J61, O31, R23

Keywords: immigration, cultural diversity, economic growth, innovation, spatial autocorrelation

Corresponding author:

Jacques Poot

National Institute of Demographic and Economic Analysis (NIDEA)

University of Waikato

Private Bag 3105

Hamilton 3240

New Zealand

E-mail: jpoot@waikato.ac.nz

\footnotetext{
* This research is part of the Migrant Diversity and Regional Disparity in Europe (MIDI-REDIE) project, funded by the NORFACE research programme Migration in Europe - Social, Economic, Cultural and Policy Dynamics. We are grateful to Jennifer Hunt, Jos van Ommeren, Giovanni Prarolo, the Institute for Employment Research (IAB) Nuremberg, and Noell Alting for comments on earlier drafts and/or the provision of data.
} 


\section{Introduction}

The more than doubling of the number of foreign-born residents of developed countries since 1980 has triggereda high level ofresearchactivity regarding the economic consequences of immigration. Yet many issues remain of concern to researchers, politicians and the general public. Much of the literature provides rather conclusive evidence that the short-run economic impact of an influx of foreigners on the host population is either positive (for example, an increase in demand; an increase in wages of those whose skills complement those of the arrivals; lower prices; a greater variety of goods and services) or only mildly negative (for example, a slight decrease of wages of those who are close substitutes for the new arrivals; an increase in the price of rental accommodation; a trade balance deterioration). ${ }^{1}$ Far less is known about the long-run economic impact. Yet the preference of many host countries to recruit highly-skilled workers (as revealed by their selection processes) is grounded in the belief that such workers will integrate more easily, reducethe amount public funding that is required for education and training, ${ }^{2}$ and boost long-run economic growth.

In this paper we focus on a specific driver of economic growth: namely, innovation, and investigate empirically whether there is a positive impact of immigration on innovation. Migrants can contribute to innovation in various ways. They contribute to the population growth of cities, which reinforces agglomeration - with positive benefits for innovation and growth (e.g. Audretch, 1998; Gordon and McCann, 2005; Kerr, 2010). Moreover, their skills, their youthfulness, and their self-selection in terms of ability, risk-taking, and entrepreneurship may positively influence innovation (e.g. Poot, 2008). Furthermore, migrants increase the ethnic and cultural diversity of the cities they settle in.It is well known, particularly since the work of Jacobs $(1961,1969)$, that more diverse cities are more innovative and prosperous.

However, the empirical research on the links between immigration and innovation is still very recent and limited to about ten studies using predominantly North American data. Given that growth in the foreign-born population since 1980 has been faster in Europe than anywhere else in the world (e.g. Longhi et al., 2010b), research on the impact of this immigration on innovation activity in Europe is warranted, and has not been conducted previously, except for astudy on German regions (Niebuhr, 2010), and another on London (Lee and Nathan, 2010). The present paper takes,therefore,a European perspective, and aims to identify the impact of immigration on patenting at a regional level across 12 European countries.

Essentially, there are five mechanisms through which immigration may boost innovation. These may be referred to as:the population sizeeffect; the population density effect; the migrant share effect;the skill composition effect; and the migrant diversity effect. The first two of these externality effects also apply to the domestic population, and will be taken into account with other local determinants of innovation. The other three are specific to immigration only, and are the focus of the paper. Our empirical research considers these effects individually, but also jointly. Of course, to operationalize

\footnotetext{
${ }^{1}$ Recent reviews include Hanson (2008), Pekkala Kerr and Kerr (2009), and Longhi et al. (2010a).

${ }^{2}$ However, Hunt (2009) finds with US data that the graduate training in the US of foreign-born workers yields a greater net benefit than recruiting workers with equivalent foreign training.
} 
such effects, we must define these externalities more precisely. For example, the host economy may benefit from an influx of highly-skilled immigrants, but also from an influx of immigrants representing a wide range of occupations. In that respect, occupational diversity may be just as important as cultural diversity. However, limited data availability necessitates the measurement of diversity only in terms of countries of citizenship.

Effectively, our research aims to find answers to three research questions. Firstly, do regions with a greater share of immigrants in the population innovate more? Secondly, what is the impact of the skill composition of the stock of immigrants on innovativeness? Thirdly and finally, does a culturally diverse society form a "contextually-enabling environment" for innovativeness? The econometric estimation exploits a two-period (1991-95 and 2001-05) panel of data on 170 NUTS 2 regions in Europe. Innovation outcomes are measured by means of the total number of patent applications. Given the geographical concentration and subsequent diffusion of innovation activity, and the spatial selectivity of immigrant settlement patterns, we take account of spatial dependence and of the endogeneity of immigrant settlement in the econometric modelling.

The perspective we take is restricted to that of the host country. The extent to which the emigration of highly-skilled workers from developing countries (the "brain drain") impacts on such countries either positively (raising post-compulsory schooling enrolment) or negatively (leading to shortages of workers in education, health, ICT and other knowledge industries) is not considered here, but we note that, if a freeing up of the international exchange of skilled labour increases the global level of innovation, diffusion of new knowledge may benefit the sending nations as well, and raise welfare there also (for a review, see Duncan, 2008).

Our results suggest that an increase in the share of the foreign-born in the population of a regionis not conclusively associated with innovation. However, an increase in the average skill level of migrants (proxied by migration from source countries from which emigrants are on average higher skilled) has a positive and statistically significant effect on patent applications. In addition, innovation levels are also positively associated with the cultural diversity of the migrant community. However, this effect appears nonlinear, and only operates beyond a critical minimum level of diversity.In Section 2, we provide a brief review of the previous literature on the effects of migration on innovation. The European data set that has been compiled to test for the impact of immigration on innovationis described in Section3. Various measurement issues are also addressed in this section. Section 4 discusses the methodology and econometric modelling. Section 5 provides a short descriptive analysis. In Section 6 we discuss a range of econometric models that measure the joint impact on innovation of the immigrant shareof the population and the skill level and ethnic diversity of the immigrants. Section 7 sums up and suggests avenues for further research.

\section{Channels of Influence of Immigration on Innovation}

As noted above, there may be many channels through which migration contributes to innovation. In a standard neoclassical setting, the main impact of immigration is distributional (Borjas, 1995). The "immigration surplus" associated with the expanding economy, accruing to the owners of capital and workers who are complements in production to migrants, is quantitatively small. While the 
associated shift of income from those supplying labour to the owners of capital may be in principle much larger, various adjustment mechanisms such as an inflow of capital in an open economy and internal migration may reduce the distributional impacts as well (see e.g. Longhi et al., 2010a). However, such comparative static analysis of the impact of immigration ignores the dynamic benefits flowing from new investment, knowledge exchange, greater product variety, and consumption externalities associated with the presence of diverseimmigrant groups (Ottaviano and Peri, 2006; Bellini et al., 2008).

Considering the first three mechanisms through which immigration may enhance innovation, population size, population density, and population share effects of immigration result from the fact that immigration boosts local aggregate demand. Such demand is partially met through additional imports, but predominantly through greater levels and greater variety of local production (Mazzolari and Neumark, 2009). While such output growth in the short run may be met by greater capacity utilization and additional labour supply (predominantly provided by the immigrants themselves), in the long run additional investment will be needed. Such new investment will embody the latest technologies, and the associated investment behaviour of firms will encourage product and process innovation. Moreover, the resulting expansion of the host economy may lead to firm growth or additional start-up firms, which will also again boost innovation (e.g. Freeman and Soete, 1997). Moreover, migrants, being predominantly attracted to the larger urban areas where job opportunities are the greatest, contribute to urban population growth, and thereby strengthen the forces of agglomerationwhich, as we noted in the Introduction,encourages greater innovation.

Given that in the modern knowledge economy technological change is an endogenous process, in whichthe production of new ideas is a function of the number of ideas workers (e.g.Lucas, 1988), the global competition for highly-skilled migrants has been intensifying. Borjas (1999) argues that immigrants are not randomly selected samples from sending countries. There is a process of selfselection in which the skilled workers who migrate may also be more entrepreneurial and less risk averse, and considerably younger (e.g. Kloosterman and Rath, 2003; Poot, 2008). Professional migrants often make multiple moves over their life course or even commute between multiple residences. This mobility behaviour generates spillover benefits to host countries in terms of transfers of new ideas and work practices. In sum, their self-selection and the host country entry regulations serve jointly as a pre-arrival melting pot.Hence, the fourth mechanism through which immigration boosts innovation is through the way in which they change the human capital stock of the host regions, by bringing in new ideas and knowledge.

Probably themain waythrough which the composition of immigration can make the host economy more innovative is through explicit admission policies that favour highly-skilled workers. Moreover, the global mobility of highly-skilled workers has been increasing sharply due to globalization, the growing importance of the knowledge economy, and transfers within transnational corporations (e.g. Poot et al. 2008). 
Both historically and at present, the world's greatest cities are inhabited by large and diverse foreign populations. ${ }^{3} T$ The issue of whether an economy containing such a diverse group of inhabitants is more productive and more creative than a more homogeneous one is a very significant policy question.City economies are complex, efficient, dynamic, and made up of myriad interacting small enterprises. In large cities many of these are run by migrant entrepreneurs, or employ migrant workers. Such enterprises increase the cultural diversity of these cities. This, in turn, encourages the proliferation of new firms and also leads to more innovative behaviour among the local firms. Similarly, firms producing differentiated outputs are also attracted to the large cities. Rapid advancements in technologies have drastically reduced the product lifecycles, which has increased the pace of product evolution. These changes encourage firms to locate in agglomerated areas. The benefits of size, density, and diversity in large cities yield higher returns to capital. Moreover, scale economies reduce transaction costs in production by generating better labour market matching between available skills and job requirements. The greater availability of heterogeneous skills in the labour market decreases costly job search and imperfect matching. Therefore, complementarities in production yield higher returns to physical and human capital (Quigley, 1998). The emergingliterature on the economics of diversity sharescommon roots with the consumption externalities literature (Florida, 2003; Clark et al., 2002; Shapiro, 2003).

Consequently, the fifth mechanism through which immigration can boost innovation is through generating greater cultural diversity in the host economy. This diversity manifests itself both on the demand side and the supply side. Jacobs (1961) argues that the city is the engine of growth of the economy and immigrants are predominantly drawn to cities. The diversity one finds in cities in terms of the variety of commercial and cultural activities, and the ways in which new ideas and creativity are boosted in diverse urban environments, is highly beneficial for long-run development. Of course, the skills of these entrepreneurial people and the city's resources should complement each other to create an enabling environment for creativity (Glaeser et al., 2010). Obviously, the variety of services provided in a city is enhanced by the presence of a culturally diverse society. Greater diversity also promotes diversified information spillovers across production sectors and processes (Glaeser et al., 1992).

However, this does not necessarily imply that increasing diversity is always beneficial. While it can be shown that, even in the standard neoclassical model,the economic benefits of immigration for the host population tend to be larger, the more dissimilar that migrants and native-born are (e.g. Borjas, 1999), excessive diversity can increase transaction costs, reduce social capital and lead to social tensions. Bellini et al. (2008) review various studies that suggest that diversity is detrimental to economic growth. Clearly, the relationship between diversity and economic performance in general may have an inverted U-shape and an optimal level of diversity may be identified in specific cases (de Graaff and Nijkamp, 2010). However, in terms of the narrower focus of diversity and innovation, there is no a priori notion of excessive diversity, but the relationship could be nonlinear.

As noted in the Introduction, empirical evidence on the association between immigrationand innovation has only emerged in recent years. Patent applicationsare often used as a proxy for innovation. Acommon feature of this empirical work so far is a strong focus on North America and

\footnotetext{
${ }^{3}$ For instance, more than 130 nationalities are represented among the residents of Amsterdam, even though this city only has a modest population of about 800,000 .
} 
highly-skilled immigrant populations. We review the US and Canadian evidence first. Hunt and Gauthier-Loiselle (2008) find that highly-skilled immigrants boost patenting at the state-level in the US without crowding out native patenting. Moreover, a college graduate immigrant contributes to patenting at least twice as much as his/her native counterpart does. This is clearly related to the disproportionate share of immigrants in the fields of science and engineering in the US.Chellaraj et al. (2008) use US time-series data to show that an increase in foreign students raises patent applications -more so than an increase in skilled immigration. A similar finding is also reported by Hunt (2009) by means of the 2003 US national survey of college graduates. She emphasizes that migrants who enter with student or trainee visas have better outcomes in wages, patenting, commercializing and licensing patents than native college graduates. Kerr and Lincoln (2010) and Kerr (2010) use an exogenous surge in the immigration of scientists and engineers in the US, due to the 1990 Immigration Act, as the means to identify the impact of immigration on the level and spatial patterns of US innovation. Especiallythe increase in Chinese and Indian patenting, referred as 'ethnic invention', has a strong correlation with admissions of foreigners by the H-1B type of visa in the US.

Zucker and Darby (2007) focus on the geographic movements of "star scientists" in the US and other countries that are ranked high in science and technology (S\&T). They find a link between their movements and innovative activity in receiving countries and regions. Star scientists, many of whom are foreign-born, tend to cluster in particular places that also attract high-tech firms, and have a strong incentive and ambition to commercialize innovations. Zucker and Darby conclude that return migration and fewer opportunities for gifted students to remain in the US after graduation may be detrimental to firm start-up and growth in the S\&T sector in that country.

Partridge and Furtan (2008) find that skilled immigrants from developed countries boost patenting in the provinces of Canada. They find that a 10percent increase in immigrants with a sufficient level of language proficiency increases the provincial patent flow by 7.3percent in Canada. Particularly immigrants with backgrounds from Western Europe and North America have such an impact. This highlights the importance of communication skills, as well as complementarities between immigrants and natives. Maré et al. (2010) use surveys of innovation activity reported by New Zealand firms (both product and process innovations) to check for a link with the presence of immigrants, and find that such an association exists at a broad spatial scale (labour market areas), but not at the level of local neighbourhoods in that country.

Finally, Niebuhr (2010) shows how cultural diversity (in terms of workers' nationalities) boosts patent applications across German regions. She uses the geography of prior immigration patterns as an instrument to identify the causal effect. The review of the available studies suggests that there is widespread, but not always robust, evidence of a positive link between immigration and innovation. Moreover, as noted earlier, this link has been rather under-researched in Europe. The present paper aims to fill this gap. 


\section{Data and Measurement Issues}

The major source of the data used in this study is Eurostat's General and Regional Database. ${ }^{4}$ The 12 European countries included in our dataset are: Austria, Belgium, Denmark, France, Germany (western), Ireland, Italy, Netherlands, Portugal, Spain, Sweden, and United Kingdom. The dataset contains information on 170 regions in those countries from 1991 until the year of most recently available data (mostly 2008-2009). It consists of five sets of indicators: (i) patent applications; (ii) population \& labour force; (iii) immigration; and (iv) production structure \& performance;and (v) geography (See Table 1). A separate document describes the data sources and modifications in detail and can be downloaded from the MIDI-REDIE project's website. ${ }^{5}$

The available data have several limitations. Firstly, data on patent applications to the European Patent Office (EPO) by regions are available only at the NUTS 2 level. ${ }^{6}$ This limits the analysis to this level, even though some regional information is available at the NUTS 3 level. Consequently, where data were only available at the NUTS 3 level, such data had to be aggregated tothe NUTS 2 level. The aggregation proved to be very time-consuming, as the coding and classification of NUTS 3 regions have changed over time.

The patent data: namely, patent applications to the EPO by IPC (International Patents Classification), are divided into eight sections. ${ }^{7}$ In the present paper we consider only the aggregate of all patents summed over the various sections. Patent applications are regionally allocated according to the inventors' place of residence. If there is more than one co-inventor, then a patent count will be equally divided by the number of inventors, which implies that fractions of a patent may be assigned to different regions and/or countries. This eliminates multiple counting and avoids overestimation of the importance of some regions as being the main generators of patent applications. The inventors of these patent applications are obviously not exclusively immigrants, and the dataset includes both non-native and native applicants. ${ }^{8}$ Given the fact that patent applications require a costly and time-consuming registration process, researchers face three major problems when using patents. Firstly, patent application procedures, which are determined by each country's central government, may vary substantially between different countries (Furman et al., 2002). Secondly, the propensity to register innovations may be culturally dependent. Thirdly, it is

\footnotetext{
${ }^{4}$ The data used in this version of the paper has been completely updated in line with Eurostat's update of regional databases in June 2010. Therefore, the estimations and descriptive statistics are based on the updated version of the source information.

${ }^{5}$ http://www.norface-migration.org/publications.php

6 The Nomenclature of Units for Territorial Statistics (NUTS) is a geocode standard for referencing the subdivisions of European countries for statistical purposes. The NUTS 1 level refers roughly to states or large regions, level 2 to provinces, and level 3 to counties.

${ }^{7}$ We use the EPO International Patents Classification (IPC) data to measure the patent applications per million inhabitants by priority year. The priority year refers to the first filing worldwide. This is therefore the year closest to the invention date. The total patent applications per million inhabitants used in this study consist of 8 IPC Sections: a) Human necessities, b) Performing operations; transporting, c) Chemistry; metallurgy, d) Textiles; paper, e) Fixed constructions, f) Mechanical engineering; lighting; heating; weapons; blasting, g) Physics, h) Electricity.

${ }^{8}$ Although the patent applications database gathered from the Eurostat website is fairly complete, there are some missing values for the United Kingdom and some other countries. Due to data deficiences, the two NUTS2 regions representing London had to be excluded. In most other cases missing values were imputed through interpolation by means of compound growth rates of patent applications. The compound annual growth rates (CAGR) are calculated over the largest possible period of time. For the selection of beginning/end values to calculate CAGR, we used beginning and end years that have no missing observations among the 170 regions.
} 
questionable that the residential location of the patent applicant always corresponds with the region where the impact is felt most strongly.

The literature provides a range of theories on the geography of innovation, ranging from incubation theory to product life-cycle theory and diffusion theory (e.g.Davelaar and Nijkamp, 2004). Nonetheless, there is broadly consensus on the local determinants of innovation production (Gordon and McCann, 2005). For instance, the demographic structure of the local population, and the information and institutional infrastructure drive the innovative potential of localities. Since innovations are indicators of the creativity of society, and have an economic value in terms of their impact on economic growth, considerable effort has been devoted to proxy visibleinnovations by means of patent applications or research grants. As a result of different classifications and intrinsic variability, it is generally accepted that patents are an imperfect proxy of innovation, although this would actually depend on the research task (Griliches, 1990).

Another data limitation is that, although many variables are available annually for the period of 1990-2008, the 'share of foreigners in the population' data (with 'foreigner' defined in terms of nationality or country of birth)are available in some countries only in 1991 and 2001 from populationcensuses. ${ }^{9}$ Moreover, the share of foreigners in the population could only be disaggregated by country of citizenship at the NUTS 2 level in 2001. Furthermore, no information is available on the skill levels of the immigrants at the NUTS 2 level, so we use the country of citizenship information as a proxy for the skills and the influence of culture that are specific to the country of citizenship. We created five major categories (Africa, America, Asia, Europe, and Oceania) as well as broader regional categories within the continents (e.g. North-America, North-Africa, Middle East, and Central and Eastern European (CEE) countries).

No information is available on the time the immigrants have spent in the host country or region, the skills acquired in the process of integration into the host country, or on the number of foreign-born migrants who were subsequently naturalized. We measure the diversity effect of immigrants on the innovativeness of the host regions by means of a fractionalization index that is calculated on the basis of the regional population by country of citizenship. ${ }^{10}$ However, since the population by country of citizenship dataset is available only for 2001, we cannot account for a change in diversity over the period 1991-2001.

Data on human resources in science and technology as a percentage of the active population aimto measure the stock of aggregate knowledge in the regions. This knowledge acts as the major input in the production of new ideas.In general,real GDP per capita is used as a good indicator of the ability of regions to convert the available knowledge into economic value (Furman et al., 2002). Yet, considering the period of analysis, we observe that many regions that were non-existent on the

\footnotetext{
${ }^{9}$ The data for 1991 were kindly provided by Giovanni Prarolo at the NUTS 3 level. German data on the share of immigrants by citizenship are available only for western Germany, and the 2001 data were provided by IAB Nuremberg, using information from the social security administration. The data refer to people who are active in the labour market, but not to their families. An estimate of the foreign-born population is obtained by dividing the number of foreign-born workers by the regional labour force participation rate. This estimate of the foreign-born population in each German region is then used to calculate the share of immigrants in the population.

${ }^{10} \mathrm{~A}$ major limitation of our measure of diversity is the absence of comparable data on the linguistic or ethnic diversity of the European regions. It is possible to extract some ethnic and linguistic diversity information from various sources mentioned in Alesina et al. (2003), but this information is available only at country level.
} 
innovation map in 1990s appeared to be strong inventors in the following decade. For that reason, we use the GDP growth rate to account for the change in the aggregate technological improvement in the regions. Since the share of GDP devoted to R\&D spending is quite constant over time, and often increasing with the development level of the region, the GDP growth rate is a good measure of increased resources that are available to the knowledge industries, rather than R\&D expenditures themselves (Hunt, 2008; Kleinknecht et al., 2002).

The size of a region's population and its density are commonly used variables to account for the impact of agglomeration on innovation. Average population size captures the available resources, the scale of production of non-traded goods and services, and the market size of the regions. Additionally, population density facilitates face to face interaction, the exchange of ideas and labour pooling. The impact of densityon productivity and innovation has been established by e.g. Ciccone and Hall (1996). The final demographic feature to be considered is the age composition of the population. Sub-national studies often find a positive correlation between the youthfulness of the population and regional economic growth or innovation activity (e.g. Poot, 2008). Of course the causality may run from regional growth to age composition since fast growing regions attract young migrants. However, the age structure changes only very slowly so that this reverse causality is unlikely to be important in our 1991-95 and 2001-2005 panel. We measure age composition by the fraction of the working population aged 25-64 that is aged 25-44.

We also obtained data on the ratio of the value added of services to thevalue added of the industrial sector in a region. We expect this variable to have a negative effect on patent applications, because patents are disproportionately generated in the high-end manufacturing sector.

A final issue of importance is that of accessibility (e.g. Reggiani et al. 2011). Clearly, knowledge spillovers require face to face interaction, and the cost of travel between the various innovation clusters is likely to matter. The accessibility index used in this study was provided by ESPON. ${ }^{11}$ The theoretical assumption behind potential accessibility is that the attractiveness of a destination increases with the size of the population and decreases with distance, travel time, or cost. These aspects are combined multiplicatively to calculate the potential accessibility:

$$
A_{i}=\sum_{j} W_{j}^{a} \exp \left(-\beta \bar{c}_{i j}\right)
$$

where $A_{j}$ is the accessibility of area $i, W_{j}$ is the opportunity(population) to be reached in area $j$; and $\bar{c}_{i j}$ is the generalized cost of reaching area $j$ from area $i . A_{i}$ is the total of the activities reachable at all areasj, weighted by the ease of getting from $i$ to each areaj. The interpretation is that the greater is the number of attractive destinations in areas $j$ and the more easily areasj are reachable from area $i$, the greater is the accessibility of area $i$. In turn, the generalized cost $\bar{c}_{i j}$ is calculated as follows:

$$
\bar{c}_{i j}=-\frac{1}{\lambda} \ln \sum_{m} \exp \left(-\lambda c_{i j m}\right)
$$

wherec $_{i j m}$ is the cost of travel by mode $m$ between $i$ and $j$, and $\lambda$ is a parameter indicating the sensitivity to travel cost. This formulation of composite travel cost is superior to average travel

\footnotetext{
${ }^{11}$ See ESPON (2009).
} 
cost, because it makes sure that the removal of a mode with higher cost (i.e. closure of a rail line) does not result in a - false - reduction in aggregate travel cost (ESPON, 2009).

The information on all variables is summarized in Table 1. With respect to diversity, the view that this may have significant economic benefits has become stronger in recent years. ${ }^{12}$ Since the turn of the millennium, several studies provide fairly robust results between innovation and diversity, starting with Duranton and Puga (2000). Diversity and cultural coherence evolve over time and through interactions between people and places. In order to measure the impact of cultural diversity on an economy, we need to acknowledge that diversity is a multi layered concept, in which ethnic, linguistic, religious and personal perceptions of belonging overlap. Among these, ethnicity may be considered a general concept which is formed by common culture and ancestry. The other dimensions such as language or religion are sub-types of ethnicity (Wimmer, 2008). Unfortunately, Eurostat data donot permit us to make such distinctions at the NUTS 2 regional level.

The diversity effect is measured by means of the fractionalization index(Alesina et al., 2003), which is calculated as follows:

$$
\operatorname{Div}_{j}=1-\sum_{i=1}^{N} s_{i j}^{2}
$$

in which $s_{i j}$ is the share of the group $i(i=1, \ldots, N)$ in region $j .{ }^{13}$ The index represents the probability that two individuals randomly selected from a sample will belong to different population groups. The minimum value of the index is 0 (complete concentration inone type), and the maximum value is 1 $1 / \mathrm{N}$. The natives are excluded from the diversity index calculations because diversity in the form of having immigrants represent is already captured by the share of immigrants in the population. In addition, natives represent the largest group in regions, which in turn leads to underestimation of the immigrant diversity. Finally, the diversity measure including natives is, using the NUTS2 data, highly correlated with the share of foreigners, whereas the diversity index excluding natives is uncorrelated with the share of foreigners. Using the latter two variables allows us therefore to identify separate effects of migrant 'density' and migrant diversity.

\section{Methodology and Econometric Modelling}

The nature of the data, a pooled cross-section of regional average characteristics, suggests that panel data techniques that account for heteroscedasticity, endogeneity,fixed effects and spatial spillovers are the most appropriate. However, the availability of data on the share of foreigners at only two points in time (1991 and 2001), and of data on the diversity among these immigrants at only one point in time (2001), limits the extent to which dynamic panel models can be utilized. Therefore, we devotemost attention to specifications that take a longer time frame per observation: namely, two pooled cross-sections of average patents (1991-1995 and 2001-2005). In this way we are also able to avoid the issue of having to specify serial autocorrelation in the presence of missing annual

\footnotetext{
${ }^{12}$ A good example is Page (2007). See also the review of this book by loannides (2010).

${ }^{13}$ Alternatively, the fractionalization index is defined as $1-H$, with $H$ the Herfindahl index of concentration of observations in certain categories of a classification.
} 
immigration data. Arguably, the longer time frame is also theoretically preferable since the impact of immigration on innovation is unlikely to manifest itself fully within a year (Griliches, 1990).

Hence, the basic specificationis as follows:

$$
\ln P_{i, t}=\mu+\mathbf{m}_{i, t}{ }^{\prime} \gamma+\mathbf{x}_{i, t}{ }^{\prime} \beta+\varepsilon_{i, t} \quad \quad \varepsilon_{i, t} \sim \mathrm{N}\left(0, \sigma^{2}{ }_{i, t}\right),
$$

where $P_{i, t}$ refers tothe five-year average patent applications per million inhabitants in region $i$ inperiod $t ; \mathbf{m}_{i, t}$ is the vector that measures the characteristics of immigration in a region; $\mathbf{x}_{i, t}$ is a vector of control variables; $\mu$ is the constant;and $\varepsilon_{i, t}$ is the error term. The coefficient vector $j$ is of central interest in our analysis, and we assess the robustness of the estimates across different specifications.

As argued earlier in the paper, there are five ways in which immigration can influence patent applications. They are: the population scale effect; the population density effect; the share of foreigners in the population; the skill composition of the migrant flow; and the diversity ofimmigrants (measured by their countries of citizenship, using the following breakdown: North Africa, Africa others, North America, America others, Middle East, Asia Others, Central and Eastern European (CEE) countries, Other European countries, Oceania, Others/unknown). Given the limitations of the data, we can only account for the varying skill levels of immigrants by grouping migrants on the basis of the average skill levels of migrants from various globalregions.

An important problem in measuring the impact of immigration on innovation is the presence of twoway causation. Immigration is likely to be endogenous. Skilled migrants in particular, may be attracted to regions where per capita income is growing, where there is considerable R\&D activity, and patent applications are likely to be increasing as well. We will use instrumental variables estimation to deal with a possible endogeneity bias. We, therefore, instrument immigration by exogenous variables. The instruments needto be correlated with immigration in the regions, but not with the error term of the model that explains the spatial, and temporal variation in patent applications.

The literature review suggested that commonly used instruments are historical migration patterns, the initial share of immigrant high school dropouts, or one-off major changes in migrant admission policies. Here we propose a novel spatial instrument that has not been previously used. The instrument should be a good proxy for international connectedness and openness that may also signal the presence of migrants, while at the same time there is little association with local innovation. For this, we searched for a multinational company that has ubiquitous establishments, but whose innovation is largely non-spatially differentiated. The company must determine the location of new outlets predominantly on the basis of population size rather than income (given the correlation between income and R\&D activity), and must be widespread all over Europe. ${ }^{14}$ The obvious candidate is the distribution of McDonald's restaurants across NUTS 2 regions. Unlike in North America and in some other parts of the world, McDonald's restaurants are considered in

\footnotetext{
${ }^{14}$ Opening new restaurants in the highly populated areas, but not necessarily high GDP areas, is also mentioned as a location choice strategy in the frequently asked questions section of the McDonald's UK's website.
} 
Europe to be a symbol of cosmopolitanism and a modern urban lifestyle among the youngrather than simply a caterer of fast food to low income people. The choice of McDonald's as an instrument fits in with the consumption externalities literature. The chain is associated with a lifestyle that is internationally connected and aims to serve a variety of people. McDonald's is also a significant employer of unskilled migrants. Consequently, a higher number of McDonald's restaurants in a region may be used a proxy for the openness and international connectedness of the region. On the other hand, the location of McDonald's restaurants is not in any way driven by patenting.

The data were collected from the McDonald's country websites, using regional locators that provide the addresses of the restaurants closest to the specified locality. Given that the greatest concentration of McDonald's restaurants is in large population areas, and that population scale is already a variable in the model, we adopt the number of McDonald's restaurants per million inhabitants in the region as an instrument.

Capital cities are for many immigrants often the first point of entry to the destination countries. On the other hand,innovation levels are not necessarily higher in those cities than in other large cities. Therefore, a dummy variable that represents the location of capital cities of the countries among the NUTS 2 level regions provides a second instrument. ${ }^{15}$

Formal tests showed that the spatial distribution of McDonald's restaurants and the capital dummy turned out to be strong instruments that explain 20percent of the cross-section variation in the share of foreign residents. Nevertheless, the capital cities are not by definition the most diverse areas. They may attract a large number of foreign short-term visitors rather than permanent residents. Indeed, the identification tests confirm that the capital dummy is a weak instrument for measuring cultural diversity. For that reason, we explore a better instrument which takes into account that the diversity of the regions depends on various economic, social and historical regional characteristics. Following Ciccone (2002), we use the total area of each of the NUTS 2 regions in $\mathrm{km}^{2}$ as an instrument, since the area of each of the regions is historically predetermined. An observed negative correlationbetweenthe area of each of the regions and cultural diversity suggest that smaller areashavegreater labour market density andpossibly labour force variety (regions that are dominated by universities are good examples, e.g. Oxford University in Oxfordshire and Cambridge University in East Anglia). The spatial distribution of McDonald's restaurants and area of the regions appear to be strong instruments that explain about 13percent of the variation of the diversity index.

Besides the issue of endogenous regressors, a pooled cross-section of regional outcomes should also take into account the possibility that the error term of the regression model is spatially correlated. There is a vast literature that argues, and provides evidence, that there are spatialknowledge spillovers, and that spatial proximity matters (Döring and Schnellenbach, 2006). Although it can be argued that the flows of knowledge and ideas are invisible (Krugman, 1991), proximity may lead to more exchange. Consequently, patent activity in any given region maybe positively affected by patent activity in surrounding regions. On the other hand, Bottazzi and Peri (2003) found that at the spatial scale of NUTS2 regions, spatial autocorrelation was actually rather minor. Nonetheless, we

\footnotetext{
${ }^{15}$ There are two exceptions to using the capital city for defining the instrument. Given the absence of London data in our dataset, the UK dummy was set equal to 1 for the Westmidlands region. In the case of Spain, the dummy was set equal to 1 for Catalunia, given the prominence of Barcelona as a migrant destination in Spain.
} 
include spatial econometric modelling in our robustness analysis. We use a row-standardized spatial weight matrix, with weights inversely proportional to the Euclidean distances between the centres of the regions. Before we report the results of both non-spatial and spatial econometric modelling in Section 6 , we first provide some descriptive analysis in the next section.

\section{Descriptive Analysis}

The number of patent applications per million inhabitants of the NUTS 2 regions per year hasmore than doubled from 55.8 in 1991 to 121.9 in 2001. The distribution across the 170 regions is given in Figure 1 for each year from 1990 until 2007.

There were26.7 millionimmigrants (foreign citizens) living in the EU12 area in 2001. They represented7.2percentof the total EU12 population. Themean (median) share of immigrants in the population across the 170 NUTS 2 regions increased from 4.8percent (3.8percent) in 1991 to 7.2percent (6.0percent) in 2001. Comparedwith the traditional immigrant-receiving countries of North America and Australasia, the percentage of foreign-born is still relatively small in manyEuropean regions. Nevertheless, there has been a relative shift of the distribution of immigrants from Western Europe to Central and Southern Europe. In recent years, the latter countries have attracted a disproportionate share ofnew immigrants. ${ }^{16}$ Figure 2 presents the distributionof the share of foreigners by NUTS 2 regions in 2001. The average across the EU12 regions (7.2percent) is also shown in this figure.

Table 2 provides descriptive statistics for the two five-year period averages that constitute most of the analysis. The five-year averages of patent applications range from 0.2 to about 812 per million inhabitants. The share of foreigners ranges from 0.1 percent to 28.6 percent of the population. The diversity (fractionalization) index that excludes the native population (index_b) has an average value of 0.494 , with a range from 0.185 to 0.805 . Including the native population, the index has an average value of 0.132 , with a range from 0.031 to 0.533 .

Our analysis period coincides with the fall of the Berlin Wall as well as the war years in the Balkans. Until 1997some countries,especially Germany, continued to welcome CEE (Central \&EasternEuropean) migrants with bilateral agreements to fill a gap in the labour market. Soon after the fall of the Iron Curtain, other Western countries implementedrestrictions in mobility from the CEE and Balkan countries. However, a migration surge was nonetheless observed from these regions towards the West that followed established ethnic networks (Straubhaar and Wolburg, 1999).Besides this network effect, two other important drivers have played a role in the migration decision: geographic and linguistic proximity. Language skills have been a crucial factor in the choice of destination (Fassmann and Hintermann,1998).There were relatively large migration movements from the aforementioned countries to Germany and Austria over the study period. Geographical proximity has also been a major factor in the migration decision. In a survey of 4000 people from the

\footnotetext{
${ }^{16}$ For instance, the foreign-born share in Vienna, Austria, became one of the highest (see Table 3), while in Spain the share of immigrants increased from 0.1 percent to 5 percent. Similarly, Italy experienced an increase from 0.1 percent to 4 percent over the same period.
} 
fourlargest countries of $\mathrm{CEE}^{17}, 48$ percent of the respondents considered geographical proximity important,and 43 percent of those considered presence of friends/relatives in the destination country central to their migration decision. In our measure of high-skilled workers in the NUTS 2 regions, we are unable to separate out those who are migrants, but several studies emphasize the inflow of a substantial number of highly-skilled immigrants from CEE countries(Straubhaar and Wolburg, 1999).

EU citizens living in another EU country than their country of origin make up the largest share (about 72percent) of all foreigners in the EU12. Africans are the next largest group, followed by Asians and Americans. Internal mobility within the EU12 (the percentage of EU born living in another EU country) is only about 2.2percent in the study period (Peri, 2005). The fiveregions with the highest share of foreignersin 2001 are shown in Table 3. With the exception of the Province-Alpes-Cote d'Azur, they are large metropolitan areas: Brussels, Vienna, Paris and Stockholm. In these citiesmore than onesixthof theinhabitants have been born in another country. Table 4 shows the five most and the five least diverse regions, based on the diversity index (excluding the natives). It is clear that some of the most diverse regions are characterized by the presence of universities: Berkshire, Buckinghamshire and Oxfordshire (Oxford University), East Anglia (Cambridge University) and Surrey, East and West Sussex. Some of the least diverse regions can be found in Belgium and Portugal. It is clear from Table 4 that a high diversity does not necessarily imply a high share of foreigners and vice versa. For example, Hainaut in Belgium has a low diversity index (0.216) but the foreign population, predominantly Other Europeans, still constitutes nearly 12 percent of the population. Moreover, even where immigrants come from different parts of the world, immigrants may be highly concentrated across a few source countries. For instance, despite immigrantshaving a large share of the population in Germany, almost 40 percent of themoriginatejust from two sources (Sudekum et al., 2009).

The scatter diagram in Figure 3suggests a positive relationship between patent applications and the share of foreigners. Linear regression lines are also presented. These show that the slope of the relationship has increased between 1991 and 2001 (the correlation coefficients are 0.33 and 0.48 , respectively). However, it is clear from the 2001 values that the highest numbers of patent applications are not necessarily in the regions where the share of immigrantsin the populationis the highest. In any case, immigrants are not homogeneous, and those regions with the highest level of patent applications may be regions where the share of highly-skilled migrants in the population is the largest, even though the overall share of immigrants may be relatively low. Moreover,as patent applications haveincreased over time they have also become more dispersed. In 1991 innovation activity was still highly concentrated in particular regions,yet spin-offs from traditional patentproducing regions resulted in innovation activity becoming more widespread in the EU12 by 2001 (see Figure 4).In the following section, we discuss our findings from multivariate analysis.

\footnotetext{
${ }^{17}$ Czech Republic, Slovakia, Poland, and Hungary.
} 


\section{Regression Results}

\section{Standard specifications}

We noted earlier in the paper that annual observations may not be the appropriate unit of measurement for considering the impact of immigration on innovation. Thus, we consider first how the share of foreigners in a year influences innovation activity in the subsequent five years, by using five-year averages of the variables that are included in the specifications reported in Table 5. This five-year averaging also controls for business-cycle effects, which are likely to have an influence on patent applications. Table 5 presents the results of three specifications of the pooled cross-section of the regional averages model. ${ }^{18}$ Specifications 5.1, 5.2 and 5.3 test, respectively, the migrant density (foreign share of the population) effect, the skill composition effect and the diversity effect of migration on innovation. In all three models, we control for time and country effects to capture the influence of national institutions and trends. ${ }^{19}$ While the data set includes 12 countries, 10 country dummies are incorporated. The Netherlands is the default country and Denmark is omitted because it constitutes only one NUTS2 region. All of the estimations also include controls for average population, GDP growth rate, regional specialization in services/industry ratio, stock of human capital in S\&T fields in the regions, and, finally, accessibility of the regions. Robust standard errors are calculated to control for cross-sectional heteroscedasticity.

As shown in Specification 5.1, the coefficient of the share of immigrants is statistically insignificant.This resultsuggests that the mere presence of foreigners in a region is not sufficient to induce innovation.Concerning the control variables, a 1percentage point increase in the GDP growth rate leads on average to a 0.05 percentincrease in patent applications per million inhabitants. Average population size is a commonly used proxy for measuring the agglomeration, demand, and consumption potential of the regions. However, population sizeis not a significant factor thatdetermines patent applications in the specifications in Table 5. The coefficient of the ratio of services over manufacturing value added is negative andstatistically significant at the 1percent level. Thus, the economy of the regions specialized in the industry sector is more prone to producing innovation applications. Our measure ofthe stock of high-skilled human resources confirms the importance of the skilled workforce for the innovativeness of a region. A 10percentage point increase in the percentage of human resources in science and technology fields in the economically active population increases patent applications by about 0.7 percent.The effectis positive and significant at the 1percent level.We also find that high accessibility is an important factor in increasing patent applications. The accessibility indicator is highly significant at the 1 percent level. The country-level dummy variables (not reported in Table 5) show that patent applications are significantly higher than average in Sweden, and lower in Ireland and the Mediterranean countries. ${ }^{20}$

\footnotetext{
${ }^{18}$ All calculations have been carried out with Stata 11.

${ }^{19}$ Given that our data consists of two waves (1991-95 and 2001-05) of cross-sectional data (170 NUTS2 regions), panel estimators could be considered in principle. However, the fixed effects estimator would omit key variables which are only available cross-sectionally at present, such as the diversity index. On the other hand, the random effects model is not the appropriate data generating process for our pooled regional averages.

${ }^{20}$ The findings on covariates of the model are fairly robust and the coefficients are quite constant over all the following estimations. Therefore, we are not going to discuss those further, and the statistical output tables are available from the corresponding author on request.
} 
Specification 5.2 in Table 5 shows how the composition of the immigrant population, in terms of their nationalities, contributes to the innovation output of European regions. We impose the same model as before, but replace the share of foreigners by variables that measure the shares of various continents in the distribution of the migrant nationalities. We are also able to disaggregate the immigrant stock by narrower groups within the continents (North Africa, other African countries, America, Middle East, Asia others, CEE, other European countries, Oceania, Other) but this does not yield notable additionalresults. Regions that have relatively many migrants from Africa and America have relatively more patent applications, while for regions with relatively many migrants from Asian countries the opposite is the case. The available data do not permit usto check whether such source region effects are due to observed skill differences or unobserved positive selection effects. The effect sizes of the coefficients of the control variables are mainlysimilar to those in Model 5.1. All variables are statistically significant at the 1 percentlevel, except the average population.

Specification 5.3 tests the influence of cultural diversity of the regional population. The coefficient of the fractionalization index is positive and statistically significant, which suggests that there are positive externalities in the form of greater innovation activity associated with culturally more heterogeneous societies. An increase in the diversity index by 0.1 (the mean value is 0.5 , see Table 2) increases patent applications per million inhabitants by about 0.16 percent.Almost all the covariates are significant at the 1percent level, meaning that, even after controlling for the effect of various factors that boost innovation, the positive contribution of diversitysurvives; hence a diverse society enhances the creativity of the regions.

To test for the robustness of our results, we consider a range of alternative specifications. These are reported in Table 6. First we replace the linear diversity effect by a quadratic form (see specification 6.1 in Table 6). The quadratic turns out to be convex, with a minimum at about 0.4. At the mean, an increase in diversity by 0.1 increases patent applications per million inhabitants by about 0.2 , which is similar to the result of the linear specification (5.4). The quadratic is plotted in Figure 5. We conclude that at low levels of diversity (roughly in the lower quartile of the distribution) an increase in diversity has a negative impact on innovation, but beyond a critical point (0.4) the benefits from cultural diversity begin toappear. The upper quartile includes regions with major universitiesand R\&D centres (see Table 4). ${ }^{21}$

We alsoreport in Table 6the joint effects of diversity and the migrant share of population on patent applications (see columns6.2 to 6.4). In Specification 6.2 we show that once density and diversity measures are simultaneously included in the estimation, the diversity effect survives significantly at the 1percent level, while we again do not find any effect of the share of foreigners. One may argue that this estimation just measuresthe marginal effects of the share of foreigners and diversity of regions on patent applications, whereas an interaction measure of those two maybe more informative about the regions which have both high density and diversity values. Consequently, the interaction term of both effects is included in Specification 6.3. The coefficient of the interaction

\footnotetext{
${ }^{21}$ When the diversity index is replaced with one that includes the native population, a concave quadratic emerges with a maximum at an index value of about 0.3 (the mean is 0.1 , see Table 2). This would suggest a notion of "optimal diversity" (see also de Graaff and Nijkamp, 2010). However, because natives still dominate in all regions, the latter index is actually highly correlated with the share of foreigners in the population and simply signals that increasing immigration is not necessarily associated with higher innovation. This is confirmed by the other specifications in Table 6 .
} 
variable is negative and statistically significant at the 5percent level. The coefficients of both the density and the diversity effect arealso statistically significant.It can be shown that the mean diversity level, increasing the share of foreigners in the population lowers patent applications slightly.

The last estimation of Table 6 reports the results for all of the five possible effects of immigration on innovation (outlined in Section 2) jointly. They are: population scale, population density, the share of foreigners, the diversity among foreigners, and the average skill level of foreigners. As noted earlier, the source country distribution is the only statistical information in the data set that we can relate to thecultural backgrounds and skills of migrants. The result in column 6.4shows the strong positive impact ofthe diversity index; hence this effect is consistent and positive in all the regressions. Thus, the cultural composition of the immigration flow does matter in stimulating more patents in a region. Secondly, an increase in the share of foreigners from other European countries (excluding Central \& Eastern Europe)boosts regional patent applications. This group of foreigners is more likely to have higher education, and there is a long shared history between these European countries which might improve economic and social integration. We do not find a particular effect of foreigners from other parts of the world on patent applications. The population scale effect is significant (but only at the 10 percent level), which suggests an agglomeration effect. The age composition variable is, contrary to expectations, negative. This may in fact simply signal an urban/rural distinction. In a European cross-section, rural regions tend to have higher fertility (e.g. Poot and Siegers, 1992) and therefore possibly a more youthful population structure. The population density effect is also significant but has a negative sign. Although this negative coefficient may seem at odds with the anticipated benefits of high urban density, at the scale of our research high regional density may not necessarily coincide with innovativeness. For example, many innovation centres are on the outskirts of the cities.Lastly, the coefficient of share of foreigners is negative but statisticallyinsignificant. Taking specification (6.4) as the most informative, we now proceed to control for potential endogeneity, and spatial dependence.

\section{Controlling for potential endogeneity}

Table 7 reports the results of the 2SLS estimations of the OLS model. Specification tests reportthenumberof McDonald's restaurantsper million inhabitants,and the capital dummyas strong instruments (F-test $>10$ ) with an explanatory power of about 20percent of the cross-section variation of the share of foreigners in regions in specification (7.1) and of the diversity index that includes natives and foreigners in specification (7.2).Diagnostic tests confirm the exogeneity of the instruments. The results tell a qualitatively similar story. It is noticeable that the impact of immigration on innovation in (7.1) and of the highly similar diversity index in (7.2) are both still insignificant, as it wasin the corresponding OLS results reported in Tables 5 and 6 .

Concerning cultural diversity among foreigners, we argue that this is not endogenous in a model of innovation. The cultural composition of the immigration flow is closely linked to exogenous national policies and historical migration patterns and not current innovation activity. However, if we include the natives in the measurement of diversity index (as in specification 7.2), the index variable certainly reveals a reverse causality problem with patent applications, due to the fact that innovative regions do attract more migrants per se. We treat this problem through IV estimation for the 
diversity index that includes natives, whilewe also include the diversity index excluding natives in this estimation to show that they are measuring different compositional patterns in regions (the simple correlation coefficient of these two indices is only -0.1370). The results show that the coefficient of the diversity index is insignificant, while the diversity index that excludes foreignersis highly significant at the 1 percent level and again in value close to 2 . The IV estimations include all the other control variables, and time/country fixed effects as the other specifications do. Therefore, the IV results donot overturn the OLS findings.

\section{Spatial econometric analysis}

Agglomeration economies, knowledge spillovers, and the role of proximity suggest that spatial effects in innovation are crucial. We generally expect that diffusion of technology is faster among regions that are close to each other. This effect may result from a supply-side externality (Vaya et al., 2004). Moreover, omitted spatially-correlated exogenous variablesand random shocks coming from neighbouring regions may influence the outcomes of regions in closeproximity (Fingleton and LopezBazo, 2006). On the other hand, Bottazzi andPeri (2003) do not find strong evidence of spatial autocorrelation at the NUTS2 level. Nonetheless, we account for spatial autocorrelation by a reestimation of the previous results by using spatial econometric models.

It is a common practice to use spatial weight matrices that are based on the pairwise distances between the cross-sectional units. The spatial weight matrices specify a form of proximity or similarity (Larch and Walde, 2008). As noted earlier, we calculateda row-standardized spatial weight matrix where we used the Euclidean distances between the centres of the regions. Becase of the panel nature of our data, the spatial weights matrix is block diagonal with positive spatial correlation and zero temporal correlation. The impact of spatial error model is best illustrated by taking Specification (5.1) as the starting point. We first omit the country fixed effects from this model and test the OLS residuals for spatial autocorrelation by means of Moran's I statistic. This suggeststhe presence of strong spatial autocorrelation in innovation modelling. Five tests have been performed to assess the spatial dependence in the model. The choice of the econometric specification is based on the statistical significance of the test statistics (Florax and de Graaff, 2004). Given heteroscedasticityof the errors in the model, robust tests are to be preferred. The robust Lagrange multiplier test indicates the presence of spatial autocorrelation in the error terms and the null hypothesis that the $\lambda=0$ is rejected at the 1 percent level (LM: 14.95, p-val.: 0.000 ). The existence of spatial correlation in the error component suggests that the independence of the observations is violated. ${ }^{22}$ An omitted variable bias due to the omission of a spatially correlated unobserved effect from neighbouring regions may lead to erroneous estimations.

Table 8 summarizes the result of replacing specification (5.1) with the spatial error model. Interestingly, we now find a positive effect of the share of foreigners but it is barely significant. The coefficients of the industrial composition, the stock of human resources in science and technology

\footnotetext{
${ }^{22}$ The spatialerror model estimates the following equations, under the assumption that there may always be spatially-correlated measurement error in the estimations, since one cannot model all the aspects of a region, e.g. the boundaries, natural resourcesand the climate of study areas may not overlap with the NUTS 2 areas. $\mathbf{y}=\mathbf{X} \boldsymbol{\beta}+\boldsymbol{\varepsilon} ; \boldsymbol{\varepsilon}=\lambda \boldsymbol{W} \boldsymbol{\varepsilon}+\mathbf{v} ; \mathbf{v} \sim N\left(0, \sigma^{2}\right) ; \lambda$ is spatiallag autoregressive parameter; $\mathbf{W}$ is a spatial weight matrix; and $\mathbf{v}$ are independently distributed errors.
} 
and the accessibility indexare again significant at the 1percent level. In contrast, the GDP growth rate is no longer statistically significant. The parameter of spatial error process is about 0.75 . However, once we reintroduce the ten country fixed effects, it can be shown that spatial autocorrelation is no longer statistically significant and the coefficients are very similar to those already reported. The same result holds in the other specifications of Tables 6 and 7. While estimators have now been developed that jointly account for endogeneity and spatial dependence (for example, Kelejian andPrucha, 2004), the fact that IV estimation in Table 7 did not overturn the OLS results, plus the statistical insignificance of the spatial error and lag model in the presence of time and country fixed effects, suggests that nothing is to be gained from such more advanced estimators. Instead, the next section draws the broad conclusions.

\section{Conclusion}

This paper has discussed the various effects of immigration on the innovativeness of the regions. We estimatedfive different effects that might occur as a result of the increasing number of foreigners in particular locations. We specifically considered the influence ofpopulation scale, population density, migrant share, the skills composition of migration, and the diversity among foreigners. To address various econometric issues such as omitted variable bias, endogeneity and spatial dependence,robustness checks were conducted through varying the specifications, introducing instrumental variables and estimating a spatial error model.

The econometric results of this paper are supportive of the view that Jacobs' externalities are important. In other words, cross-fertilization of ideas in a diverse urban area creates a contextual environment where more ideas are produced and turned into innovative outputs. The two important findings of this work are:firstly, the regions with relatively many immigrants do not have a positive or negativeimpact onthe production of a higher number of patent applications; and secondly, the diversity of abilities brought by the immigrants may be beneficial and complementary to the native workers in the host regions. These results hold even after robustness checks with IV and spatial estimation. The varying degrees of cultural differences in terms of horizontal differentiation create opportunities for culturally diverse regions. However, we also found that there is a critical point beyond which these benefits from diversity may begin to occur.Among the NUTS2 regions, this point occurs beyond the first quartile of the diversity distribution. For the benefits gained from diversity to appear, diversity among foreigners living and working in a particular locality needs to be above a threshold level. We also conclude that the index of fractionalization that is commonly used to measure diversity, namely the one that includes the native born population, is not an appropriate measure of the intended diversity effect. Instead, it simply proxies (and is highly correlated with) the share of foreigners in the population, i.e. just the 'exposure' of natives to foreigners rather than the diversity among the latter.

Innovation is strongly driven by industrial composition, GDP growth, human resources in science and technology, and accessibility. Hence higher competitiveness and availability of knowledge spillovers in a culturally diverse setting contributes to the innovativeness of the regions in Europe. We found that immigrant groups from certain source regions have a more positive and significant effect on patent applications than those from other regions. However, better data are needed to studyhow a 
variation in the composition of the immigrant flow may affectthe economic output on the host economy.

Generally, we had considerable data availability problems at the NUTS2 regional level that impede us from pursuing more comprehensive research on this topic. However, the available data do permit an analysis of the impact of immigration on innovation by patent type, which will be conducted in a future paper. More generally, analysis at the micro-level may be more fruitful and we have already commenced research along these lines, combining firm data on innovation with matched data on employee characteristics in The Netherland. Such research maybehelpful in designing immigration policies which can ensure the best economic and social outcomes. Such targeting based on perceived host country outcomes is already the main motivation for the points systems that are used to select skilled migrants in Australia, Canada, New Zealand, and the United Kingdom.

\section{References}

Alesina, A., Devleeschauwer, A., Easterly, W., Kurlat, S. and Wacziarg, R. 2003. Fractionalization.Journal of Economic Growth, 8: 155-194.

Audretch, D. 1998.Agglomeration and the Location of Innovative Activity.Oxford Review of Economic Policy, 14:18-29.

Bellini, E., Ottaviano, G.I.P., Pinelli, D. and Prarolo, G. 2008.Cultural Diversity and Economic Performance: Evidence from European Regions. HWWI Research Paper 3-14, Hamburg Institute of International Economics.

Borjas, G.J. 1999. The Economic Analysis of Immigration, In: O. Ashenfelter and D. Card edsHandbook of Labor Economics, North Holland, 1697-1760.

Borjas, G.J. 1995. The Economic Benefits from Immigration.Journal of Economic Perspectives, 9(2): 3-22.

Bottazzi, L. and Peri, G. 2003.Innovation and Spillovers in Regions: Evidence from European Patent Data. European Economic Review, 47(4):687-710.

Chellaraj, G.C., Maskus, K.E. and Mattoo, A. 2008.The Contribution of International Graduate Students to US Innovation. Review of International Economics 163: 444-462.

Ciccone, A. 2002.Agglomeration effects in Europe. European Economic Review. 46: 213-227.

Ciccone, A. and Hall, R.E. 1996. Productivity and the Density of Economic Activity. American Economic Review 86(1): 54-70.

Clark, T. N., Lloyd, R., Wong, K. K. and Jain, P. 2002. Amenities Drive Urban Growth. Journal of Urban Affairs, 24: 493-515.

Davelaar, E.J. and Nijkamp, P. 2004.Spatial Dispersion of Industrial Innovation. In:Innovation, Space and Economic Development: Selected Essays of Peter Nijkamp. Edward Elgar Publishing.

deGraaff, T. and Nijkamp, P. 2010. Socio-Economic Impacts of Migrant Clustering on Dutch Neighbourhoods: In Search of Optimal Migrant Diversity. Socio-Economic Planning Sciences, 44: 231-239

Döring, T. and Schnellenbach, J. 2006. What Do We Know about Geographical Knowledge Spillovers and Regional Growth? : A Survey of the Literature.Regional Studies, 403(3): 375-395.

Duncan, N.T. 2008. Brain Drains, Brain Gains and Migration Policies.In: J. Poot, B. Waldorf and L. van WissenEdsMigration and Human Capital, Cheltenham UK. 
Duranton, G. and Puga, D. 2000. Diversity and Specialisation in Cities: Why, Where and When Does it Matter?Urban Studies, 37(3): 533-555.

ESPON. 2009. Update of Air and Multimodal Potential Accessibility Indicators Final Report, March 2009, by Klaus Spiekermann.Spiekermann\& Wegener Urban and Regional Research (S\&W).

Eurostat.2010.Regional Statistics Database. Accessed at various dates in June 2010.http://epp.eurostat.ec.europa.eu/portal/page/portal/region_cities/regional_statistics/d ata/database

Fassmann, H. and Hintermann, C. 1998. Potential East-West Migration Demographic Structure, Motives and Intentions.Czech Sociological Review, 6(1): 59-72.

Fingleton,B. and López-Bazo, E. 2006. Empirical Growth Models with Spatial Effects.Papers in Regional Science, 85(2): 177-198.

Florax, R. J. G. M. and de Graaff, T. 2004. The performance of diagnostic tests for spatial dependence in linear regression models: a meta-analysis of simulation studies. In: Advances in Spatial Econometrics, Edited by L. Anselin, R. J. G. M. Florax and S. J. Rey. Berlin: Springer-Verlag.

Florida, R. 2003.Cities and the Creative Class.City \& Community 2:1 March.

Freeman, C. and Soete, L. 1997.The Economics of Industrial Innovation, $3^{\text {rd }}$ ed. Routledge.

Furman, J.L., Poter, M. and Stern, S. 2002.The Determinants of National Innovative Capacity.Research Policy 31: 899-933.

Glaeser E.L., Kallal H.D., Scheinkman J.A. and Shleifer A. 1992.Growth in Cities.Journal of Political Economy, 100: 1126-1151.

Glaeser, E.L., Rosenthal, S.S. and Strange, W.C. 2010.Urban Economics and Entrepreneurship.Journal of Urban Economics, 67(1): 1-14.

Goedings, S. 1999. EU Enlargement to the East and Labour Migration to the West. International Institute of Social History Research Paper 36, Amsterdam.

Gordon, I.R. and McCann, P. 2005. Innovation, Agglomeration, and Regional Development.Journal of Economic Geography5: 523-543.

Griliches, Z. 1990. Patent Statistics as Economic Indicators: A Survey. Journal of Economic Literature, 28(4): 1661-1707.

Hanson, G.H. 2008. The Economic Consequences of the International Migration of Labor, NBER Working Paper 14490, National Bureau of Economic Research, Cambridge Mass.

Hunt, J. 2009. Which Immigrants are Most Innovative and Entrepreneurial? Distinctions by Entry Visa. NBER Working Paper 14920, National Bureau of Economic Research, Cambridge Mass.

Hunt, J. and Gauthier-Loiselle, M. 2008. How Much Does Immigration Boost Innovation? NBER Working Paper 14312, National Bureau of Economic Research, Cambridge Mass.

Jacobs, J. 1969. The Economy of Cities, Random House, New York.

Jacobs, J. 1961.The Death and Life of the Great American Cities.Random House, New York.1993 Modern Library Edition.

Kelejian, H.H. and Prucha, I.R. 2004.Estimation of Simultaneous Systems of Spatially Interrelated Cross Sectional Equations.Journal of Econometrics, 118: 27-50.

Kerr, W.R. 2010.Breakthrough Inventions and Migrating Clusters of Innovations.Journal of Urban Economics, 67: 46-60.

Kerr, W.R. and Lincoln, W. 2010. The Supply Side of Innovation: H1-B Visa Reform and US Ethnic Invention.NBER Working Paper 15768, National Bureau of Economic Research, Cambridge Mass.

Kleinknecht, A., van Montfort, K. and Brouwer, E. 2002.The Non-Trivial Choice between Innovation Indicators. Economics of Innovation and New Technologies, 112: 109-121.

Kloosterman, R. and Rath, J. 2003.Immigrant Entrepreneurs: Venturing Abroad in the Age of Globalization. Berg Publishers. 
Krugman, P. 1991.Geography and Trade.MIT Press.

Larch, M. and Walde, J. 2008.Lag or Error? - Detecting the Nature of Spatial Correlation. Studies in Classification, Data Analysis, and Knowledge Organization. ISSN 1431-8814, Springer.

Lee, N. and Nathan, M. 2010. Knowledge Workers, Cultural Diversity and Innovation.International Journal of Knowledge-Based Development, Vol. 1, No. 1/2, pp. 53-78.

Longhi, S., Nijkamp, P. and Poot, J. 2010a.Joint Impacts of Immigration on Wages and Employment: Review and Meta-analysis.Journal of Geographical Systems, 12(4): 355-387.

Longhi, S., Nijkamp, P. and Poot, J. 2010b. "Meta-analyses of Labour Market Impacts of Immigration: Key Conclusions and Policy implications. Environment and Planning C: Government and Policy, 28: 819-833.

Lucas, R. 1988. On the Mechanics of Economic Development.Journal of Monetary Economics 22: 342.

Maré, D.C., Fabling, R. and Stillman, S. 2010.Immigration and Innovation.Commissioned by the Economic Impacts of Immigration research programme of the Department of Labour. Wellington: Department of Labour.

Mazzolari, F. and Neumark D. 2009. Beyond Wages: The Effects of Immigration on the Scale and Composition of Output. NBER Working paper 14900, National Bureau of Economic Research, Cambridge Mass.

Niebuhr, A. 2010. Migration and Innovation: Does Cultural Diversity Matter for Regional R\&D Activity? Papers in Regional Science, 89: 563-585.

Ottaviano, G.I.P and Peri, G. 2006. The Economic Value of Cultural Diversity: Evidence from US Cities. Journal of Economic Geography, Vol. 6, No. 1, pp. 9-44.

Ozgen, C., van Eijndhoven, E., Nijkamp, P. and Poot, J. (2010).Data Manual - Immigration and Innovation in European Regions.Available from the website of the Norface research programme Migration in Europe - Social, Economic, Cultural and Policy Dynamics. http://www.norface-migration.org/publications.php

Page, S.E. 2007.The Difference: How the Power of Diversity Creates Better Groups, Firms, Schools, and Societies. Princeton University Press.

Partridge, J. and Furtan, H. 2008. Increasing Canada's International Competitiveness: Is There a Link between Skilled Immigrants and Innovation? Paper presented at the American Agricultural Economics Association Annual Meeting, Orlando FL, July 27-29.

Pekkala Kerr, S. and Kerr, W. 2009.Economic Impacts of Immigration: A Survey. Harvard Business School Working paper 09-013.

Peri, G. 2005. Skills and Talent of Immigrants: A Comparison between the European Union and the United States. Discussion paper no. 050304. Institute of European Studies, UC Berkeley, http://repositories.cdlib.org/ies/050304

Poot, J. 2008. Demographic change and regional competitiveness: the effects of immigration and ageing. International Journal of Foresight and Innovation Policy,4(1,2): 129-145.

Poot, J. and Siegers, J.J. 1992.An Economic Analysis of Fertility and Female Labour Force Participation in New Zealand.New Zealand Economic Papers 26(2): 219-248.

Poot J., Waldorf, B. and van Wissen, L. eds 2008.Migration and Human Capital. Edward Elgar, Cheltenham UK.

Quigley, J.M. 1998. Urban Diversity and Economic Growth. The Journal of Economic Perspectives, 12(2): 127-138.

Reggiani, A., Bucci, P. and Russo, G. 2011.Accessibility and Impedance Forms: Empirical Applications to the German Commuting Network. International Regional Science Review, 34(2): 230-252.

Shapiro, J.M. 2003. Smart Cities: Explaining the Relationship between City Growth and Human Capital. NBER working paper.National Bureau of Economic Research, Cambridge Mass.

Straubhaar, T. and Wolburg, M. 1999.Brain Drain and Brain Gain in Europe.JahrbücherfürNationalökonomie undStatistik 218: 574-604. 
Sudekum, J., Wolf, K. and Bien, U. 2009.Cultural Diversity and Local Labour Markets, IZA Discussion paper 4619.IZA Institute for the Study of Labor, Bonn.

Vaya, E., Lopez-Bazo, E., Moreno, R., Surinach, J. 2004.Growth and Externalities across Economies: An Empirical Analysis using Spatial Econometrics. In L. Anselin, R. Florax and S. Rey eds.Advances in Spatial Econometrics. Methodology, Tools and Applications, Berlin: SpringerVerlag.

Wimmer, A. 2008.The Making and Unmaking of Ethnic Boundaries.A Multi-Level Process Theory.American Journal of Sociology, 113(4): 970-1022.

Zucker, L.G. and Darby, M.R. 2007.Star Scientists, Innovation and Regional and National Immigration.National Bureau of Economic Research, Cambridge Mass. 
Table1: The data used in the estimations

\begin{tabular}{|c|c|c|c|c|c|}
\hline Indicators & Code & Measures & NUTS & Years & Datasource \\
\hline 1 Patent applications & $\mathrm{p}$ & $\begin{array}{l}\text { Total patent applications per million inhabitants } \\
\text { (pmi) }\end{array}$ & NUTS2 & $1990-2005$ & Eurostat, EPO \\
\hline \multirow{3}{*}{$\begin{array}{l}2 \text { Population \& labour } \\
\text { force }\end{array}$} & ave & Average population of the calendar year & NUTS3/NUTS2 & 1990-2006 & Eurostat \\
\hline & $\mathrm{pd}$ & Population density (total pop/km²) & NUTS3/NUTS2 & 1990-2005 & Eurostat \\
\hline & $\mathrm{hr}$ & $\begin{array}{l}\text { Human resources in science } \& \text { tech. as a share of } \\
\text { active population }\end{array}$ & NUTS2 & 1994-2007 & Eurostat \\
\hline \multirow[t]{3}{*}{3 Immigration } & shfor & Share of foreigners in total pop. & NUTS3/NUTS2 & 1991, 2001 & Eurostat, IAB, CENSI \\
\hline & index_b & $\begin{array}{l}\text { Fractionalization index }=1 \text {-Herfindal index of } \\
\text { nationality shares (excl. natives) }\end{array}$ & NUTS2 & 2001 & Own calculations \\
\hline & index & $\begin{array}{l}\text { Fractionalization index }=1 \text {-Herfindal index of } \\
\text { nationality shares (incl. natives) }\end{array}$ & NUTS2 & 2001 & Own calculations \\
\hline \multirow[t]{2}{*}{$\begin{array}{l}4 \text { Production structure } \& \\
\text { performance }\end{array}$} & smv & $\begin{array}{l}\text { Service sector value added divided by industry } \\
\text { sector value added }\end{array}$ & NUTS3/NUTS2 & $1990-2008$ & Oxford econometrics \\
\hline & gdpgr & GDP growth rate (\%) & NUTS3/NUTS2 & $1990-2005$ & Oxford econometrics \\
\hline \multirow[t]{4}{*}{5 Geography } & w & Weight matrix based on Euclidean distance & NUTS2 & - & ETIS \\
\hline & mcdst & $\begin{array}{l}\text { Number of McDonald's restaurants per million } \\
\text { inhabitants }\end{array}$ & NUTS2 & 2009 & Own calculations \\
\hline & area & Area of the regions $\left(\mathrm{km}^{2}\right)$ & NUTS2 & $1990-2005$ & Eurostat \\
\hline & access & Accessibility index & NUTS2 & 2009 & ESPON \\
\hline
\end{tabular}

Note: Full details on the data can be found in Ozgen et al. (2010). 
Table 2: Descriptives - 170 NUTS 2 regions

\begin{tabular}{|c|c|c|c|c|}
\hline Variables & Mean & Std.Dev. & Min & Max \\
\hline Patent applications per million inhabitants 1991-1995* & 61.8 & 70.9 & 0.2 & 320.2 \\
\hline Patent applications per million inhabitants 2001-2005* & 127.5 & 128.5 & 1.3 & 811.9 \\
\hline Share of foreigners in 1991 & 0.048 & 0.042 & 0.001 & 0.286 \\
\hline Share of foreigners in 2001 & 0.072 & 0.042 & 0.016 & 0.273 \\
\hline Ratio of services over industry value added1991-1995* & 2.47 & 0.98 & 0.96 & 7.74 \\
\hline Ratio of services over industry value added2001-2005* & 3.09 & 1.34 & 0.85 & 11.03 \\
\hline GDP growth rate (\%)1991-1995* & 1.68 & 3.03 & -5.24 & 11.59 \\
\hline GDP growth rate (\%) 2001-2005* & 1.78 & 1.68 & -1.49 & 8.11 \\
\hline Average Population1991-1995 (000s)* & 1914 & 1582 & 116 & 10806 \\
\hline Average Population2001-2005 (000s)* & 1988 & 1657 & 121 & 11313 \\
\hline Human resources in S\&T as \% of active pop.1991-1995* & 29.83 & 7.19 & 12.36 & 55.02 \\
\hline Human resources in S\&T as \% of active pop.2001-2005* & 34.88 & 6.83 & 13.42 & 55.16 \\
\hline Accessibility index 2006 & 104.77 & 32.30 & 39.49 & 197.27 \\
\hline Population density1991-1995(pop. per km²)* & 335.84 & 648.81 & 3.12 & 5936.5 \\
\hline Population density2001-2005 (pop. per km²)* & 345.00 & 655.02 & 3.30 & 6033.5 \\
\hline Area of regions $\left(\mathrm{km}^{2}\right) 1991-1995^{*}$ & 14905 & 19736 & 161 & 165079 \\
\hline Area of regions $\left(\mathrm{km}^{2}\right) 2001-2005^{*}$ & 14929 & 19767 & 161 & 165296 \\
\hline Population aged 25-44 / aged 25-64 1991-1995* & 0.5767 & 0.0293 & 0.4973 & 0.7101 \\
\hline Population aged 25-44 / aged 25-64 2001-2005* & 0.5634 & 0.0258 & 0.4871 & 0.6417 \\
\hline Fraction of Africans $2001 * *$ & 0.0073 & 0.0103 & 0.0004 & 0.0766 \\
\hline Fraction of Americans $2001^{* *}$ & 0.0041 & 0.0066 & 0.0002 & 0.0533 \\
\hline Fraction of Asians $2001^{* *}$ & 0.0069 & 0.0116 & 0.0002 & 0.0863 \\
\hline Fraction of Central and Eastern Europeans 2001** & 0.0052 & 0.0093 & 0.0001 & 0.0790 \\
\hline Fraction of Other-Europeans $2001 * *$ & 0.0467 & 0.0327 & 0.0084 & 0.1690 \\
\hline Diversity index including natives in 2001 & 0.1321 & 0.0779 & 0.0312 & 0.5331 \\
\hline Diversity index_b excluding natives in 2001 & 0.4945 & 0.1716 & 0.1853 & 0.8054 \\
\hline McDonald's restaurants per million pop. in 2008 & 13.49 & 7.08 & 0 & 33.64 \\
\hline
\end{tabular}

Notes: * The individual observations are the five-year averages of the annualvalues for each NUTS 2 region.

**The fraction of foreigners, from the given continents, among total populationin 2001. 
Table 3: Regions with the highest and lowest share of foreigners (shfor) in 2001

\begin{tabular}{|c|c|c|c|}
\hline 2001 & $\begin{array}{c}\text { NUTS } 2 \\
\text { Codes }\end{array}$ & Regions & $\begin{array}{c}\text { Share of } \\
\text { foreigners }\end{array}$ \\
\hline \multirow{5}{*}{ 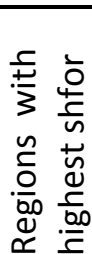 } & BE1 & Brussels & 0.272 \\
\hline & AT13 & Wien & 0.236 \\
\hline & FR1 & Il de France & 0.180 \\
\hline & SE01 & Stockholm & 0.176 \\
\hline & FR82 & Province-Alpes-Cote d'Azur & 0.173 \\
\hline \multirow{5}{*}{ 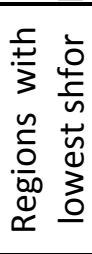 } & FR25 & Basse-Normandie & 0.029 \\
\hline & ES13 & Cantabria & 0.028 \\
\hline & FR52 & Bretagne & 0.028 \\
\hline & BE23 & Flandre Orientale & 0.027 \\
\hline & ES41 & Castilla y Leon & 0.026 \\
\hline
\end{tabular}

Table 4: The most and least diverse regions with respect to the continental sharesof foreigners(\%) in 2001

\begin{tabular}{|c|c|c|c|c|c|c|c|c|c|c|}
\hline 2001 & $\begin{array}{l}\text { NUTS } 2 \\
\text { Codes }\end{array}$ & Regions & $\begin{array}{l}\text { Diversity index } \\
\text { index_b }\end{array}$ & $\begin{array}{c}\text { Share of } \\
\text { foreigners }\end{array}$ & Afr & Ame & Asi & Eur & Rest & Total \\
\hline \multirow{5}{*}{ 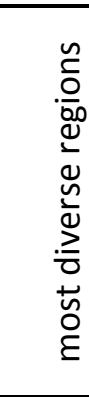 } & UKJ1 & $\begin{array}{c}\text { Berkshire, Bucks and } \\
\text { Oxfordshire }\end{array}$ & 0.805 & 0.107 & 0.23 & 0.16 & 0.26 & 0.3 & 0.05 & 1.00 \\
\hline & ES23 & La Rioja & 0.781 & 0.053 & 0.24 & 0.31 & 0.10 & 0.35 & 0.00 & 1.00 \\
\hline & UKH1 & East Anglia & 0.775 & 0.063 & 0.11 & 0.23 & 0.22 & 0.39 & 0.04 & 1.00 \\
\hline & UKJ3 & $\begin{array}{c}\text { Hampshire and Isle of } \\
\text { Wight }\end{array}$ & 0.775 & 0.062 & 0.16 & 0.13 & 0.31 & 0.36 & 0.04 & 1.00 \\
\hline & UKJ2 & $\begin{array}{c}\text { Surrey, East and West } \\
\text { Sussex }\end{array}$ & 0.774 & 0.085 & 0.24 & 0.10 & 0.35 & 0.28 & 0.03 & 1.00 \\
\hline \multirow{5}{*}{ 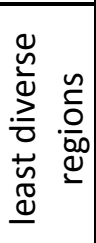 } & PT16 & Centro & 0.232 & 0.055 & 0.05 & 0.07 & 0.00 & 0.87 & 0.01 & 1.00 \\
\hline & PT11 & Norte & 0.225 & 0.040 & 0.05 & 0.06 & 0.01 & 0.87 & 0.01 & 1.00 \\
\hline & BE32 & Hainaut & 0.216 & 0.118 & 0.07 & 0.02 & 0.01 & 0.89 & 0.01 & 1.00 \\
\hline & BE34 & Louxembourg & 0.197 & 0.044 & 0.05 & 0.01 & 0.02 & 0.91 & 0.01 & 1.00 \\
\hline & BE22 & Limbourg & 0.185 & 0.080 & 0.06 & 0.01 & 0.02 & 0.91 & 0.00 & 1.00 \\
\hline
\end{tabular}

Note:For comparability the diversity index values given here referto the continental shares instead of a complete breakdown into sub continents. 
Table 5: Pooled OLS estimation with period data (1991-1995 and 2001-2005)

Dep.var.: $\ln ($ Patents)

Share of foreigners

$-0.942$

(1.356)

Diversity index_b $b^{\mathrm{a}}$

$1.578^{* * *}$

Africans

$10.99 *$

$(0.392)$

\begin{tabular}{|c|c|c|c|}
\hline Africans & & $\begin{array}{l}10.99 * \\
\text { (6.598) }\end{array}$ & \\
\hline Americans & & $22.44^{*}$ & \\
\hline & & $(11.58)$ & \\
\hline Asians & & $-15.78 * *$ & \\
\hline & & (6.859) & \\
\hline Central \& Eastern Europeans & & 19.82 & \\
\hline & & $(13.12)$ & \\
\hline Other Europeans & & -0.747 & \\
\hline & & (2.039) & \\
\hline Services/industry sectors value added & $\begin{array}{c}-0.245 * * * \\
(0.0633)\end{array}$ & $\begin{array}{c}-0.270 * * * \\
(0.0758)\end{array}$ & $\begin{array}{c}-0.244^{* * *} \\
(0.0589)\end{array}$ \\
\hline GDP growth rate & $0.0520 * * *$ & $0.0560 * * *$ & $0.0563 * * *$ \\
\hline & $(0.0189)$ & $(0.0195)$ & $(0.0186)$ \\
\hline In(total population) & 0.0572 & 0.0865 & 0.0678 \\
\hline & $(0.0613)$ & $(0.0613)$ & $(0.0582)$ \\
\hline Human resources in S\&T & $0.0669 * * *$ & $0.0562 * * *$ & $0.0592^{* * *}$ \\
\hline & $(0.0103)$ & $(0.0100)$ & $(0.0102)$ \\
\hline Accessibility index & $0.0133 * * *$ & $0.0112 * * *$ & $0.0113^{* * *}$ \\
\hline & $(0.00237)$ & $(0.00233)$ & $(0.00218)$ \\
\hline Constant & -0.191 & 0.0562 & -0.446 \\
\hline & $(0.833)$ & (0.839) & (0.773) \\
\hline Time/Country FE & Yes/Yes & Yes/Yes & Yes/Yes \\
\hline $\mathrm{N}$ & 340 & 340 & 340 \\
\hline R-squared & 0.795 & 0.804 & 0.803 \\
\hline
\end{tabular}

Notes: ${ }^{\mathrm{a}}$ This index includes only foreign population.

Robust standard errors in parentheses, $* * * p<0.01, * * p<0.05, * p<0.1$, 
Table 6: Sensitivity Checks ${ }^{1}$

Dep.var.: $\ln$ (Patents)

(6.1)

(6.2)

(6.3)

(6.4)

Share of foreigners

$\begin{array}{cccc} & -0.0787 & 7.834^{* *} & -3.217 \\ & (1.377) & (3.232) & (2.335) \\ -5.666^{* * *} & 1.574 * * * & 2.464 * * * & 1.842^{* * *} \\ (1.507) & (0.391) & (0.535) & (0.562) \\ & & -17.50 * * * & \end{array}$

Interaction of shfor*index_b

(6.596)

Diversity index_b $b^{2}$

$7.548 * * *$

(1.608)

Ln(total population)

0.063

0.068

$0.061 \quad 0.093 *$

(0.058)

(0.058)

(0.057)

(0.057)

Population density

$-0.0003^{* *}$

(0.0001)

Youthfulness of pop.

$-3.212^{* *}$

(1.509)

Other Europeans

8.221**

(3.720)

Constant

1.187

$-0.454$

$-0.960$

0.807

(0.824)

(0.810)

(0.790)

(1.251)

Time/Country FE

Yes/Yes

Yes/Yes

Yes/Yes

Yes/Yes

$\mathrm{N}$

340

340

340

340

R-squared

0.813

0.803

0.807

0.825

Notes: ${ }^{1}$ The estimations in this table include the following covariates: services/industry sectors value added, GDP growth rate, In(total population), human resources in S\&T, accessibility index. Additionally, Africans, Americans, Asians and Central \& Eastern Europeans categories are included in the fourth estimation, but they are not reported in column (6.4) to save space. All the latter coefficients are statistically insignificant. Robust standard errors in parentheses, $* * * p<0.01, * *$ $p<0.05, * p<0.1$. 
Table 7: Instrumental Variables Estimations ${ }^{1}$

\begin{tabular}{lcc}
\hline Dep.var.: In(Patents) & $(7.1)$ & $(7.2)$ \\
& & \\
\hline & & \\
Share of foreigners & -7.005 & \\
& $(7.283)$ & \\
Diversity index & & \\
& & $(4.355$ \\
Diversity index_b & & $1.835^{* * *}$ \\
& & $(0.493)$ \\
Constant & -0.915 & 0.103 \\
& $(1.179)$ & $(1.098)$ \\
Time/Country FE & Yes/Yes & Yes/Yes \\
\hline $\mathrm{N}$ & 340 & 340 \\
R-squared & 0.783 & 0.803
\end{tabular}

Notes: ${ }^{1}$ The estimations in this table include the following covariates: services/industry sectors value added, GDP growth rate, In(total population), human resources in S\&T, accessibility index. ${ }^{\alpha} T$ his index includes the foreign and native population.Share of foreigners is instrumented with spatial distribution of McDonald's restaurants per million inhabitants and a capital dummy, while the diversity index is instrumented with the former, and area of the regions. Robust standard errors in parentheses, $* * * p<0.01, * * p<0.05, * p<0.1$.

Table 8: Estimations of Spatial Effects

Dep.var.: $\ln$ (Patents)

Share of foreigners

$3.458^{*}$

$(1.861)$

Services/industry sectors value

$-0.319 * * *$

added

\begin{tabular}{lc} 
& $(0.0795)$ \\
GDP growth rate & 0.0200 \\
& $(0.0241)$ \\
In(total population) & -0.0624 \\
& $(0.0667)$ \\
Human resources in S\&T & $0.0861^{* * *}$ \\
& $(0.0128)$ \\
Accessibility index & $0.0144^{* * *}$ \\
& $(0.00263)$ \\
Constant & 0.579 \\
& $(0.998)$ \\
Time/Country FE & Yes/No \\
\hline $\mathrm{N}$ & 340 \\
\hline Lambda & $0.751^{* * *}$ \\
& $(0.151)$ \\
LR & -465.2 \\
LM & 21.51 \\
\hline N
\end{tabular}

Note: Robust standard errors in parentheses, ${ }^{* * *} p<0.01,{ }^{* *} p<0.05, * p<0$. 


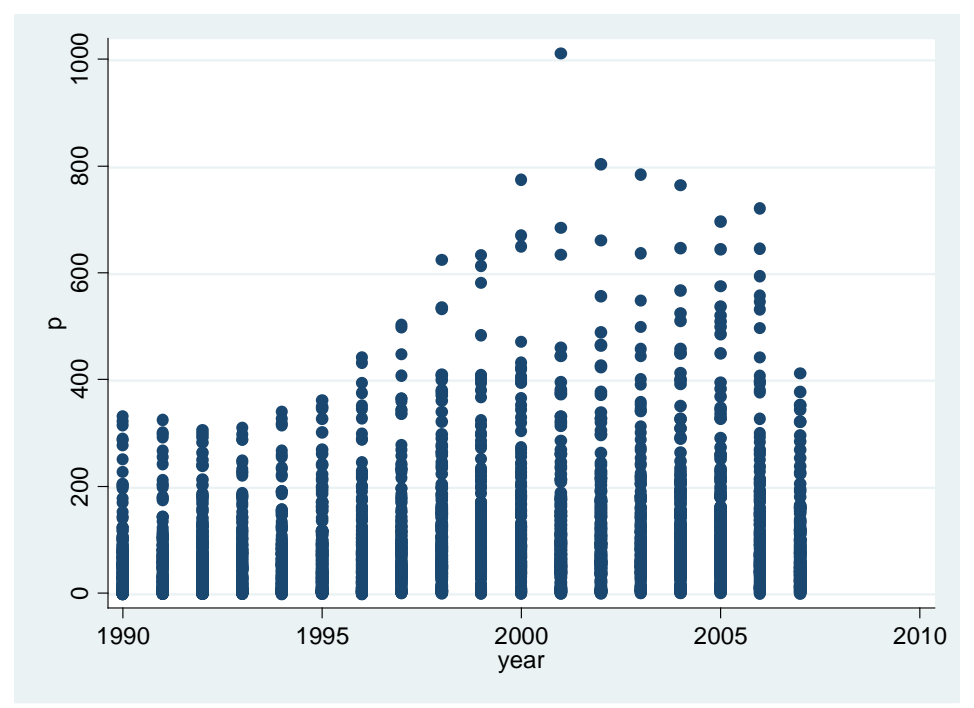

Figure 1: Distribution of patent applications across NUTS 2 regions, 1990-2007

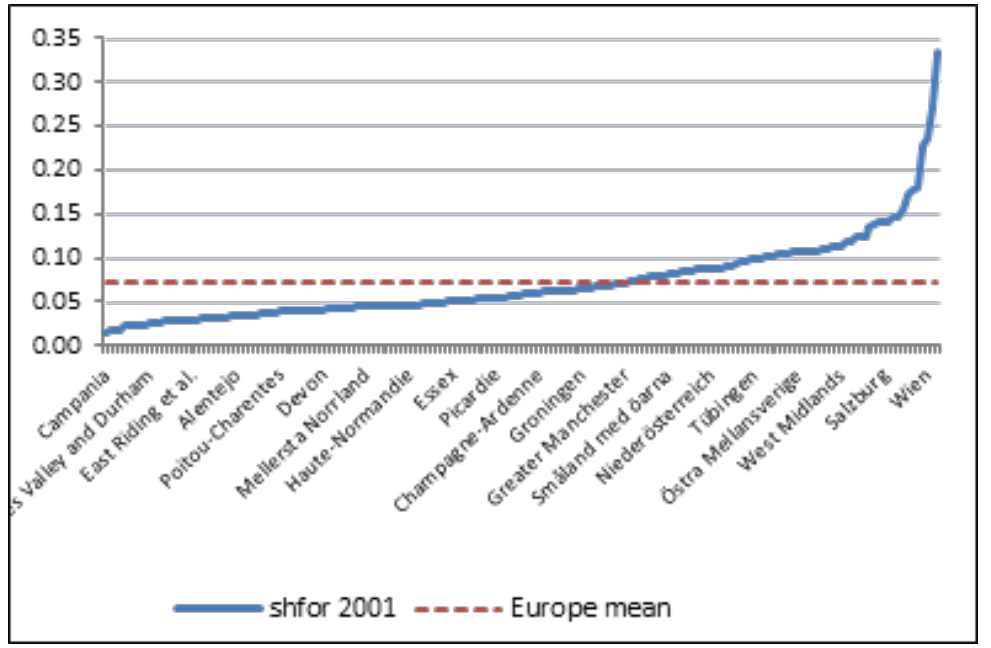

Figure 2: Distribution of the share of foreigners in Europe in 2001

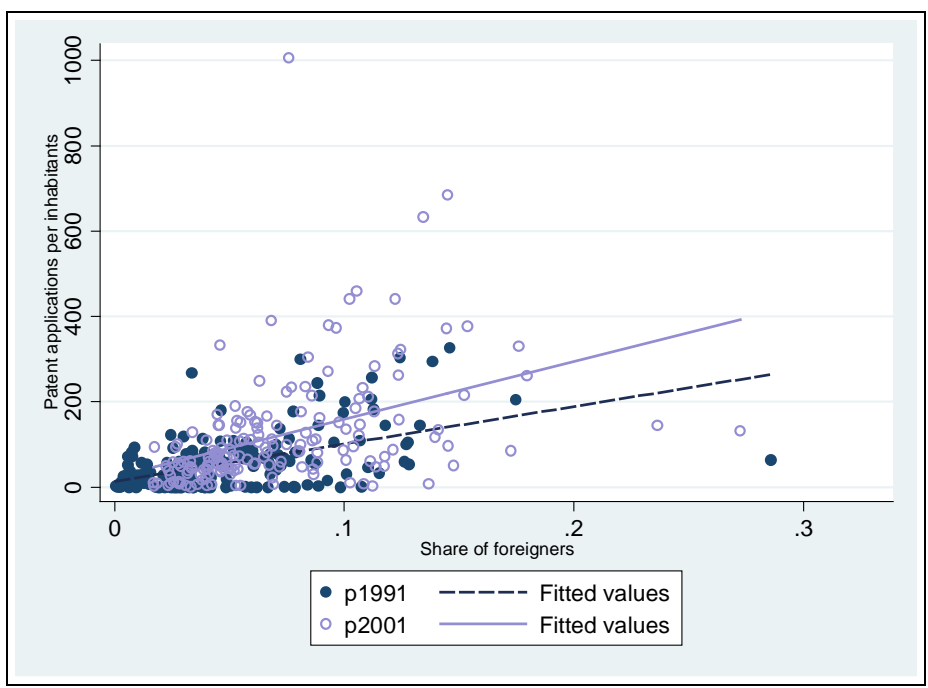

Figure 3: Scatter plot for patent applications per inhabitants vs share of foreigners in the regions in 1991 and 2001 


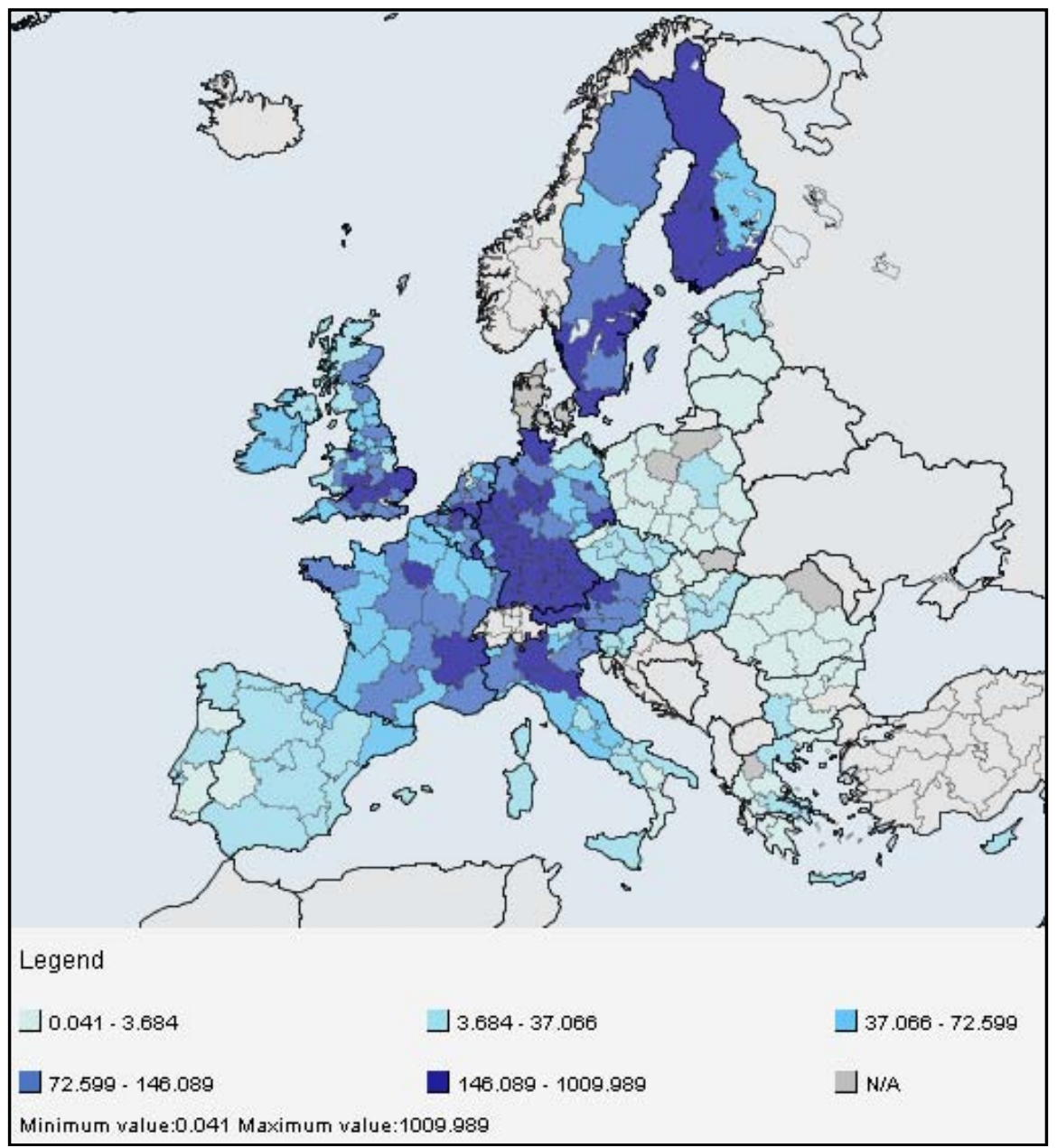

Figure 4: Patent Applications by Regions in 2001

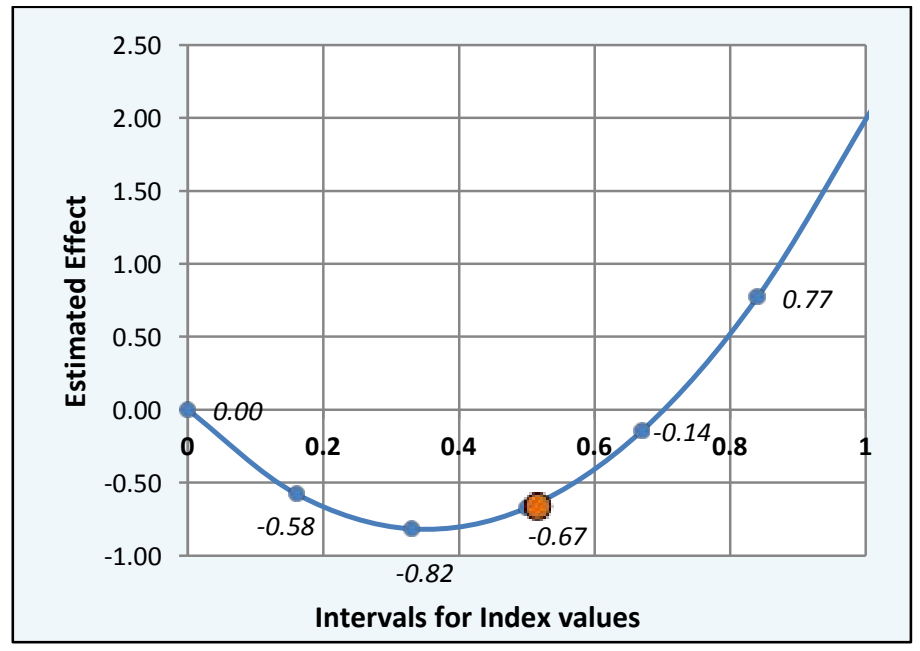

Figure 5: Estimated effect sizes for diversity index (excluding natives) 